\title{
Teachers in Primary Education: The Choice between the New Contents Learned in Higher Education and the Same Old Methodologies
}

\author{
Marcio Lima do Nascimento ${ }^{1}$, Marcos Monteiro Diniz ${ }^{2}$ \\ ${ }^{1}$ Center for Innovation and Technologies Applied to Education and Extension (Nitae), Federal University of Pará (UFPA), Belém, \\ Brazil \\ ${ }^{2}$ Institut of Exact and Natural Sciences (ICEN), Federal University of Pará (UFPA), Belém, Brazil \\ Email: marcion@ufpa.br, mdiniz@ufpa.br
}

How to cite this paper: do Nascimento, M. L., \& Diniz, M. M. (2021). Teachers in Primary Education: The Choice between the New Contents Learned in Higher Education and the Same Old Methodologies. Creative Education, 12, 1314-1322.

https://doi.org/10.4236/ce.2021.126099

Received: January 24, 2021

Accepted: June 15, 2021

Published: June 18, 2021

Copyright $\odot 2021$ by author(s) and Scientific Research Publishing Inc. This work is licensed under the Creative Commons Attribution International License (CC BY 4.0).

http://creativecommons.org/licenses/by/4.0/

\begin{abstract}
This paper presents a research carried out in the Amazon, specifically in the state of Pará, Brazil, where the implementation of workshops in the field of elementary mathematics presented to teachers from Pedagogy degree. To develop such a proposal, the workshop is centered on two main issues: Discussion on triggering vectors of some topics in arithmetic and geometry that are part of the content taught to students from the first to the fifth year; questionnaire on which methods of these topics are taught to students or whether teachers choose only one method for each topic and/or whether they use new (active?) methodologies learned during graduation. The results and the speeches indicate that traditional methods are widely used. On the other hand, teachers who participated in the workshops are strongly willing to change their strategies in teaching elementary mathematics to children.
\end{abstract}

\section{Keywords}

Creative Education, Elementary Mathematics Workshops, School Practice

\section{Introduction}

The current work presents a research carried out in the Amazon Region, specifically in the state of Pará, Brazil, where workshops in the field of elementary mathematics (some topics in arithmetic and geometry) were presented to graduates and students at the end of their Pedagogy course, in PARFOR (Brazilian National Teacher Training Plan by CAPES, Ministry of Education of Brazil) at Federal University of Pará. To develop such a proposal, the workshops were 
centered on two main issues: 1) Discussion on triggering vectors of some topics in arithmetic and geometry that are part of the content taught to students from the first to the fifth year (with teachers licensed in pedagogy); 2) questionnaire on the methods taught to students or whether teachers choose only one method for each topic and/or whether they use new (active?) methodologies learned during graduation.

Lappan \& Schram (1989) say that any mathematics class should incorporate "spaces" where the student can reason and communicate his ideas. The authors add that it is necessary for the teacher to listen to the students and ask them to explain their thinking, giving students time to explore, formulate problems, develop strategies, make conjectures, think about the validity of these conjectures, discuss, argue, predict and ask questions. This is still a valid and current guideline, but the teachers' complaint of excessive content and lack of time to carry it all out remains in the 21st century-we can observe it in some of the data provided by workshop participants. On the other hand, they have the notion that when they teach mathematics to children from the first to the fifth grades, they become learning facilitators and that learning becomes more meaningful as the students take longer thinking mathematically. It is obvious that these procedures may be clear in other areas, but in these classes in Pará, it seems that the traditional class still prevails. This is a real challenge for those who teach mathematics: the relationship between the content dosage and the student's authentic speech on the subject (we will see more details on the concept of authentic speech in the next section). An important step is to review certain pedagogical practices in the development of key concepts in arithmetic, which generate more flexibility and sharpen the child's creativity so that they do not get the impression that math problems are algorithms with only one solution, with only one way to solve them. This is done with mathematics at all levels, from the pure mathematics researcher to the beginning child. Mathematics has to be lively and instigating for the student.

The main reference that inspired the arithmetic workshops was Liping Ma's book: Knowing and Teaching Elementary Mathematics: Teachers' Understanding of Fundamental Mathematics in China and the United States (Ma, 1999), which compares the strategies of Chinese teachers with those of American teachers. The author also weaves ample alternatives for changes in the ways of knowing and teaching elementary mathematics. Furthermore, this Ma suggests that teachers' knowledge of mathematics may contribute to a tradition of mathematics in the classroom and its alteration. A "shared mathematical understanding" that marks a tradition cannot be dissociated from the mathematical knowledge of people in the classroom, especially from the knowledge of the teacher who is in charge of the teaching process. If the teacher's own knowledge of mathematics taught in elementary school is limited to procedures, how can we expect his or her classes to have a tradition of mathematical inquiry? The author hopes that the change will only occur if everyone works to change teachers' mathematical 
knowledge. It was along these lines that we thought of the mathematics teachers' workshops, discussing and sharing elementary mathematics, adapting to the Amazonian reality.

\section{Methodology}

This work clearly combines quantitative and qualitative approaches, the mixed method. According to (Creswell \& Clark, 2018: p. 116):

A mixed methods case study is a type of mixed method study in which the quantitative and qualitative data collection, results, and integration are used to provide in-depth evidence for a case(s) or develop cases for comparative analysis. ... This mixed methods design is consistent with the basic idea of a case study that focuses on developing a detailed understanding of a case (or multiple cases) through gathering diverse sources of data.

During the workshops, this qualitative research consisted of a case study and the application of a questionnaire to the participants-the mixed method mentioned above. We first interviewed tutor teachers (TU) who taught the workshops and several teacher-students (TS) from the municipal educational system who participated in the activities. The workshops were held in February and July, vacation months, of 2017, 2018 and 2019. It is important to note that the workshops are the result of an extension project entitled "Mathematics Workshops: theorizing and practicing with the teacher-students of the Pedagogy Course/PARFOR at UFPA" developed by the teachers from the College of Mathematics of UFPA as a partnership with PARFOR. They occurred in the intervals between the academic years (in the months of May/November), for three days. The project comprised 17 workshops, as shown in Table 1 below. The conformation of the workshops has changed over the years. Initially, a basic text was prepared with the authors and the tutors involved. Then, the strategies were changed in order to standardize the actions at the poles, trying not to escape the main points to be discussed-this is the reason for the inclusion of the videos triggering the discussions. The workshops aim to discuss the critical points of basic knowledge of mathematical contents taught in the initial series, as well as to present new methodological choices that elicit students' learning and that effectively make mathematical knowledge accessible to all, through innovative methodologies. These methodologies enable meaningful learning in mathematics, and, mainly, rework the old alternatives with a different look.

Turning to the aspect of linking old to new strategies, the mathematics workshops were structured with these connecting vectors, where the teacher may perceive that his or her strategies can be improved, aiming at the facilitation of meaningful learning. As Amatuzzi would say, we search for rescuing the student's authentic speech, which can break the vicious circle:

To educate oneself is to learn the expressiveness of the word that speaks (and it is not just spoken); to learn to speak (in the strong sense of the term). Thus the relationship between education, learning, creativity and expressivity becomes evident (Amatuzzi, 1989: p. 15). 
Table 1. Table of pole cities.

\begin{tabular}{|c|c|}
\hline \multicolumn{2}{|c|}{ Locations and number of workshops held } \\
\hline Pole cities & Number of workshops \\
\hline Abaetetuba & 02 \\
\hline Acará & 01 \\
\hline Altamira & 02 \\
\hline Breves & 02 \\
\hline Cachoeira do Arari & 01 \\
\hline Cametá & 01 \\
\hline Castanhal & 01 \\
\hline Colares & 01 \\
\hline Concórdia do Pará & 01 \\
\hline Ipixuna & 01 \\
\hline Goianésia & 01 \\
\hline Nova Esperança do Piriá & 01 \\
\hline Traquateua & 01 \\
\hline São Caetano de Odivelas & 01 \\
\hline TOTAL NUMBER OF WORKSHOPS & 17 \\
\hline
\end{tabular}

\section{Workshop Structure}

When looking at the content prepared for the workshops (Nascimento et al., 2015), one can get the impression that it is a traditional arithmetic course on the four elementary operations of mathematics: addition, subtraction, multiplication and division of numbers, the study of fractions and proportions and a small study of the concept of area in geometry. However, all the teachers had already studied these subjects in different traditional ways at some point in their lives, and many of them were teaching the subjects with the plans of their schools and have different experiences. Doing a simple and "the same as usual" workshop on arithmetic didn't interest us. We wanted to highlight key points when addressing certain contents, which could lead to changes aimed at children's creativity. We will see in the next subsection how the structure of these workshops was designed.

The key points mentioned above (we will see in detail in the next section) were elaborated by the organizers of the workshop, the authors of this article, in the form of trigger vectors for discussion and inspired in Liping Ma's book (Ma, 1999). The videos guide the discussion at each pole and the rest of the workshop is taught by tutors, who are Master's students in mathematics. The main purpose of the videos was to nudge, awaken and start the process of change in the reframing of concepts. Each workshop accepted 30 students. 


\section{Data Collection and Case Study}

While evaluating the students' performance in the workshop, an interview with the tutors showed that, during the classes, the perception of the students in reassessing their practices was evident when the contents of multiplication and multiplication tables was approached. They were asked if the result of the practice was "memorizing or learning". This change can be clearly noticed when one of the participants said "I really want them to memorize!" (TU1). After the workshops, he changed his opinion and started to share the principle that it is more valuable that the students learn and know how to build the multiplication table because he agrees that it will be a more concrete and lasting learning.

One of the teacher-students of the workshop highlights this difficulty that their students had in understanding the multiplication table:

When students arrive, they have difficulty with basic operations: multiplication, division. They cannot understand the relationship between division and multiplication. (TS1)

We understand that the students' difficulties derive from a mechanical teaching method. For example, in the case of multiplication, memorization is based on repeated construction (by successive additions) and exhaustive reading multiplication tables. Memorization should occur, for instance, by using hands and fingers, in a playful and fun way to build and understand the multiplication table that gives meaning to the student. In addition, the gaps in teacher training will immediately reflect on the students' learning, and we can observe this issue in the words of TS2:

There are many things I did not see during my training. I did not see during my study period and graduation does not teach everything, and when we go to the classroom, we face the difficult. (TS2)

Note that we do not know if the teacher had actually seen the new methodologies during his undergraduation program and forgot them afterwards, since its syllabus has subjects that discuss active methodologies. Other possibility is that he simply decided to adopt what he learned in Elementary School. This is considered an important issue and is mentioned in the title of the article.

The words of another tutor demonstrate this difficulty in teaching mathematics:

When we attended the workshops there was a lot of times that I said, "Wow! That's how it's done?". I could not have made my student's life so difficult. It should have been simpler. (TU3)

We believe that this reflects a very common situation: lack of knowledge regarding other teaching methodologies. This gap makes teachers end up reproducing practices from the times when they were students. When asked about this issue, some tutors pointed out:

You should not teach your students the methods that were used in your training. They may be outdated. New discussions are needed for children to innovate. Methods for understanding subtraction of integers numbers and operations with fractions, for example, are fundamental for understanding basic ma- 
thematics. (TU4)

The vast majority of teachers in China learn and teach subtraction by regrouping and many other ways. Here in Brazil we follow the American model of teaching subtraction by borrowing only. Ten out of ten. Brazilian students only subtract by borrowing. This limitation oppresses creativity and throws mathematics into the darkness [accessible only] to initiates and geniuses. (TU3)

We believe that the meetings enabled the teacher-students of the workshops to rethink their attitudes, their practices, their teaching methodologies, since valuable issues were raised and brought reflection, as shown by these testimonies:

This form that the teacher brought us reminded me of difficulties in my childhood. How did I have a hard time learning this and now it's so easy?! The teacher always left a message for us: that not everyone learns the same way, the student can have other ways. (TS4)

Today you need to make the student want to learn to like math, break this label of being a difficult subject. We come from a traditional background and the workshop brought a light, showed that mathematics is very present in the students' everyday routine. (TS5)

After analyzing the opinions of tutors and teacher-students, we understand that the workshops were extremely important to establish a dialogue between the participants towards the development of a critical reflection that instigated doubt as a starting point for change. In this sense, error is one of the steps to improve in order to build valid and meaningful knowledge. See a reflection by a team member after the workshop planning meetings:

Why is it that in meetings of friends if someone says he or she hates math everyone laughs? Nobody is ashamed of that. I don't see people who have the courage to say that they hate music or that they hate reading books, although sometimes they don't read a book a year and enjoy a poor quality music. We have to change that. (TU3)

Lima (2008) observes that the teacher training needs to be resized or the school is in danger of entering a process of emptying its social function. It is essential that the teacher feels the need to reflect on his knowledge, his practices and his know-how; however, it needs not only that reflection, but that it takes place in a collective space. To exercise his function, the teacher increasingly needs knowledge about his work, schoolwork and himself. See another testimony from a student teacher:

I have been teaching in this city for so long and they have never told me about mathematics in this way, that it can be less inflexible, that I can speak of fractions at the same time that I speak of division, of percentage and everything is related to measuring with a ruler, so geometry is involved. I feel like tearing up the syllabus of the subject that was always strictly followed and the students hated it. (TC5)

TC5's words reflect in a way the core of the workshops: everything is related! And, as teachers, we must trace the path of knowledge that pleases us, but also leaves the students more able to learn, giving them the opportunity to find their 
ways, which can be quite different from ours. Therefore, in these training spaces, we must present alternative methodological tools, without the need for many technological and/or high-cost resources. And this shows us that the teacher needs to stop, evaluate, debate and question whenever necessary, in order to increase the degree of participation of the subjects in the teaching and learning process.

\section{The Questionnaires}

The questionnaires were designed with direct questions about which method on each subject was emphasized by the teacher in his or her practice. The subjects are listed below:

- subtraction by regrouping versus subtraction by borrowing

- playful multiplication versus memorization of multiplication tables

- area by axioms ideas versus area formulas

For example, in the case of the area topic, the question was: did you define the area element using the square of unitary area and the ideas behind the area axioms or just using area formulas?

To illustrate the topic involved in the question about subtraction, consider the following example: in the subtraction $37-18$, the subtraction by borrowing indicates that we have first to borrow 1 from the 3 in the tens space, converting this 1 in ten ones to add to 7 , obtaining 17 and finally subtract 8 . Then we have $17-8$, which again is not a direct calculation for the children. After, in the tens space, we have to subtract 1 from the remaining 2 , resulting 1 . Finally we obtain 19. On the other hand, the subtraction by regrouping indicates that we can proceed $37-18$ in many ways, see one of the ways below:

$$
\begin{aligned}
& 37=10+10+10+7 \\
& \frac{-18=-10-8}{0+2+10+7=19}
\end{aligned}
$$

In the regrouping method, the creativity of the students is stimulated and they can even do everything mentally. That is the goal.

Analyzing the results of the questionnaires (Table 2), it is interesting and disturbing to notice that subtraction by borrowing, a method that many students have enormous difficulty in using to proceed their calculations, is widely used in Pará with an average of $97 \%$ although other methods are included in official textbooks. Everyone who teaches subtraction by borrowing method says that they learned just that way and find it impressive that Chinese students train regrouping and do it mentally throughout their lives.

On the other hand, playful methods of multiplication are present in an average of $28 \%$, but again the mechanical memorization methods are preponderant. The calculation of area is a major problem because in fact teachers have no idea of how to approach the concept of area. This causes serious problems for children in learning geometry. We have to change this, and the active methodologies have to be discussed in school. 
Table 2. Results of questionnaires.

\begin{tabular}{|c|c|c|c|}
\hline \multicolumn{4}{|c|}{ Locations and results } \\
\hline Pole cities & $\begin{array}{c}\text { Subtraction by } \\
\text { regrouping }(\mathrm{SR}) \\
\text { versus subtraction } \\
\text { by borrowing }(\mathrm{SB})\end{array}$ & $\begin{array}{c}\text { Memorizing } \\
\text { multiplication tables } \\
(\mathrm{MT}) \text { versus use of } \\
\text { playful methods (PM) }\end{array}$ & $\begin{array}{l}\text { Area using axiom } \\
\text { ideas (AA) versus } \\
\text { mechanical } \\
\text { memorization } \\
\text { method (MM) }\end{array}$ \\
\hline Abaetetuba & SB: $87 \%$ & MT: $75 \%$ & MM: $98 \%$ \\
\hline Acará & SB: $98 \%$ & MT: $76 \%$ & MM: $100 \%$ \\
\hline Altamira & SB: $99 \%$ & MT: $65 \%$ & MM: $100 \%$ \\
\hline Breves & SB: $99 \%$ & MT: $74 \%$ & MM: $100 \%$ \\
\hline Cachoeira do Arari & SB: $100 \%$ & MT: $81 \%$ & MM: $100 \%$ \\
\hline Cametá & SB: $95 \%$ & MT: $60 \%$ & MM: $96 \%$ \\
\hline Castanhal & SB: $85 \%$ & MT: $62 \%$ & MM: $98 \%$ \\
\hline Colares & SB: $100 \%$ & MT: 77\% & MM: $100 \%$ \\
\hline Concórdia do Pará & SB: $100 \%$ & MT: $78 \%$ & MM: $100 \%$ \\
\hline Ipixuna & SB: $100 \%$ & MT: 79\% & MM: $100 \%$ \\
\hline Goianésia & SB: $100 \%$ & MT: $80 \%$ & MM: $100 \%$ \\
\hline Nova Esperança do Piriá & SB: $99 \%$ & MT: $68 \%$ & MM: $100 \%$ \\
\hline Traquateua & SB: $100 \%$ & MT: $72 \%$ & MM: $100 \%$ \\
\hline São Caetano de Odivelas & SB: $100 \%$ & MT: $62 \%$ & MM: $100 \%$ \\
\hline Average in Pará & $\begin{array}{c}\text { SB: } 97 \% \text {, } \\
\text { SR: } 3 \%\end{array}$ & $\begin{array}{l}\text { MT: } 72 \%, \\
\text { PM: } 28 \%\end{array}$ & $\begin{array}{c}\text { MM: } 99 \% \text {, } \\
\text { AA: } 1 \%\end{array}$ \\
\hline
\end{tabular}

\section{Final Considerations}

The study carried out here intended to collaborate with the discussions on teacher education, especially that of teachers studying pedagogy through the National Teacher Training Plan (PARFOR) in Pará and brought the experience of teaching mathematics through workshops, which sought evidence of the need for these changes in pedagogical practice in search of creativity.

In view of the analysis of the recurrent testimonies of teachers and students, we noticed the great task of educational institutions, mainly in the state of Pará, where we observed the worst educational rates in Brazil. It is a result, among other causes, of insufficient investments for the valorization and training of teachers in undergraduate courses. An important issue is also what to do with the most basic mathematics, the one discussed in the pedagogy curricula. Is it enough to discuss mathematics in these courses? Therefore, we emphasize that initiatives like these, carried out through extension projects that reach teachers on the school floor, are of great value. The university-school partnership is one of the necessary ways to rethink the teacher education and training strategies to improve this reality and make mathematics more attractive to students. Discussing math with joy and fun is more interesting than discussing past failures in 
teaching mathematics in pedagogy courses. Listening to these teachers and being able to help improve their practice was an immeasurable gain, because we know that it reverberates in the classroom.

\section{Acknowledgements}

The authors would like to thank to PROPESP/UFPA for financial support and are grateful to the 17 tutors who taught the workshops, students of the master's degree in mathematics, who dedicated themselves to the topic of teaching mathematics to children.

\section{Conflicts of Interest}

The authors declare no conflicts of interest regarding the publication of this paper.

\section{References}

Amatuzzi, M. M. (1989). O resgate da fala autêntica:filosofia da psicoterapia e da educação. Campinas, SP: Papirus Editora.

Creswell, J., \& Clark, V. L. P. (2018). Designing and Conducting Mixed Methods Research. London: CSAGE Publications.

Lappan, G., \& Schram, P. (1989). Communication and Reasoning: Critical Dimensions of Sense Making in Mathematics. In Trafton, P. R., \& Shulte, A. P. (Eds.), New Directions for Elementary School Mathematics: Yearbook (pp. 14-30). Reston, VA: NCTM Inc.

Lima, E. R. C. (2008). A Caminho da Aprendizagem da Docência: os dilemas profissionais dos professores iniciantes. In: Veiga, A. P. I., \& D’Avila, C. (orgs), Profissão Docentes Novos Sentidos, Novas Perspectivas. São Paulo: Papirus.

Ma, L. P. (1999). Knowing and Teaching Elementary Mathematics: Teachers' Understanding of Fundamental Mathematics in China and the United States. Mahwah, NJ: Lawrence Erlbaun Associates Publishers. https://doi.org/10.4324/9781410602589

Nascimento, M. L., Cordeiro, L. A. C., Sá, D. J. C., Braga, F. R. C., Teixeira Jr, G. A., Rosa, P. A. L., Albuquerque, O. D., \& Lopes, E. R. L. (2015). Matemática para pedagogia: Oficina de Aritmética. Belém: EditAedi, 1, 125 p. https://pt.calameo.com/read/0050623436f7bbf7b0307 